Brit. J. industr. Med., 1963, 20, 1.

\title{
ASBESTOSIS IN EXPERIMENTAL ANIMALS
}

\author{
BY \\ J. C. WAGNER* \\ From Pneumoconiosis Research Unit, Council for Scientific and Industrial Research, Johannesburg
}

(RECEIVED FOR PUBLICATION JULY 27, 1962)

\begin{abstract}
Previous animal experiments with asbestos dusts have been almost entirely confined to chrysotile asbestos. It was, therefore, decided to investigate the effects of mill dusts from the three types of asbestos that are produced commercially in South Africa, namely chrysotile, amosite, and crocidolite. Chrysotile and amosite samples were relatively pure while in contrast the crocidolite dust was found to consist mainly of ironstone and silica and contained less than $10 \%$ of asbestos fibre. Guinea-pigs, Vervet monkeys, and rabbits were exposed to these dusts. The results were assessed on histological criteria. It was found that, in all three species of animals, the amosite dust produced more marked lesions than the chrysotile and that these lesions occurred at an earlier period. It was not possible to compare these lesions with those caused by the crocidolite dust, owing to its impure nature. It was noted, however, that this dust caused severe lesions in guinea-pigs and monkeys and that the animals in this group succumbed more readily to respiratory infections.
\end{abstract}

Early animal experiments with asbestos were almost entirely confined to the investigation of chrysotile. According to Simson (1928), Mavrogordato had conducted a small dusting experiment with Rhodesian chrysotile asbestos at the beginning of 1925. Guinea-pigs were exposed to the dust for two hours a day for 50 days. One animal died in December 1927, and histological examination of sections from the lungs showed the presence of a slight generalized fibrosis with asbestos bodies in the air spaces.

In 1928, Gardner and Cummings started a long series of animal experiments with asbestos, of which preliminary results appeared in 1931 and 1938. This work was completed by Vorwald, Durkan, and Pratt, and was published in 1951. Gardner and Cummings were able to demonstrate the presence of peribronchiolar fibrosis in guinea-pigs that had been dusted for 600 days with chrysotile asbestos. (A number of these animals were injected with the Trudeau $R_{1}$ strain of tubercle bacillus, and, although this exacerbated the lesions, the effect was not as severe as it had been when this organism had been used in conjunction with silica dust.) These authors were unable to produce lesions in rabbits after 300 days of dusting. In the results of further experiments, reported in 1938, Gardner showed that

*Present Address: Pneumoconiosis Research Unit, Llandough Hospital, Llandough, Nr. Penarth, Glamorgan. finely-ground asbestos dust, with a fibre length of less than $3 \mu$, failed to produce the lesions associated with larger fibres, in spite of the fact that the dust concentrations were four times greater. Gardner also found that the lesions regressed if the animals exposed to the larger fibres were removed from dusting. These findings were confirmed by Vorwald and his co-workers in 1951. In addition, these workers carried out a series of intratracheal experiments, using various types of asbestos including amosite and crocidolite. They found that both these minerals produced similar lesions to those found in animals exposed to chrysotile. It appeared, therefore, that the long fibres were toxic, while the short fibres were relatively inert.

King, Clegg, and Rae (1946) conducted intratracheal experiments with rabbits, using Rhodesian chrysotile fibres of $2.5 \mu$ and $15 \mu$ in length. They concluded that the short fibres produced a generalized interstitial fibrosis, whereas the long fibres produced nodular lesions, comparable with silicotic nodules. This, however, was not confirmed in later experiments using rats (Smith, Wootton, and King, 1951). In these animals short fibres did not produce lesions.

These experiments left some doubt as to the toxicity of fine chrysotile dust, and they failed to produce lesions that simulated those seen in moderate or marked cases of human asbestosis. 
TABLE

PARTICLE SIZE ANALYSIS SHOWING PERCENTAGE OF EACH DUST IN EACH SIZE RANGE

\begin{tabular}{|c|c|c|}
\hline Dust & Size $(\mu)$ & Per Cent. \\
\hline Fine chrysotile & $\begin{array}{c}<0 \cdot 3 \\
0 \cdot 3<1 \cdot 0 \\
1 \cdot 0-2 \cdot 2 \\
>2 \cdot 2\end{array}$ & $\begin{array}{r}58.5 \\
29.0 \\
11.0 \\
1.5\end{array}$ \\
\hline Amosite & $\begin{array}{c}<0 \cdot 3 \\
0.3<1 \cdot 0 \\
1 \cdot 0-2 \cdot 2 \\
>2 \cdot 2\end{array}$ & $\begin{array}{r}52 \cdot 0 \\
30 \cdot 6 \\
8 \cdot 0 \\
9 \cdot 4\end{array}$ \\
\hline Impure crocidolite & $\begin{array}{c}<0.3 \\
0.3<1 \cdot 0 \\
1 \cdot 0-2 \cdot 2 \\
>2 \cdot 2\end{array}$ & $\begin{array}{r}53.8 \\
31.8 \\
6.0 \\
8.4\end{array}$ \\
\hline
\end{tabular}

The statement made by Gardner and Cummings (1931) and re-emphasized by Vorwald and his coworkers in 1951 that the lesions in experimental animals tended to regress after the animals were removed from the dusty atmosphere does not correlate with observations on human cases exposed to asbestos dust (Hunter, 1957). Apart from the few intratracheal experiments reported by Vorwald and his colleagues (1951) no information was forthcoming on the effects caused by the inhalation of amphibole dusts in experimental animals.

It was decided, therefore, to conduct a series of experiments using mill dusts from the three types of asbestos produced commercially in South Africa, i.e. chrysotile, amosite, and crocidolite. These experiments, which have been referred to previously (Wagner, 1958 and 1960), were assessed histologically.

\section{Material and Methods}

Animals.-Guinea-pigs, rabbits, and Vervet monkeys were used. The guinea-pigs and rabbits were obtained from the stock of the South African Institute for Medical Research. The monkeys were captured in the coastal forests of Natal, and were then acclimatized for six weeks under laboratory conditions before being exposed to the dusts.

Dust.-The three types of asbestos dust were obtained from the collecting bags of the cyclone exhausts in the mills.

Exposure.-Animals were dusted in rooms 10 cubic feet in size by the method described by Webster (1954). This method had to be slightly modified when coarser amphibole dusts were used. It was found that if these dusts were blown against the ceiling towards the middle of the room the dust appeared to be well dispersed. This was achieved by attaching a right-angled length of piping to the dust jet. Animals were dusted for eight hours a day over a period of five days a week. Once a year, dusting was stopped for three weeks for maintenance purposes.
The dust concentration was estimated by a thermal precipitator, and the dust-feeding mechanism was calibrated in an attempt to keep the dust cloud at the required concentration. Variation in the dust counts occurred from day to day, and "peaking" occurred on some occasions. However, average counts over weekly periods were close to the required concentration. Counts were taken at various times during the day. The thermal precipitator is not an ideal instrument for measuring the concentration of fibrous dusts, since the longer fibres are not drawn into the instrument. Redispersed samples of the bulk material of the various dusts showed the presence of between 7 to $10 \%$ of fibres longer than $10 \mu$.

\section{Experiment I: Chrysotile.}

(a) Animals.-Twenty-four guinea-pigs, two rabbits, and three Vervet monkeys were exposed. The guinea-pigs were killed at monthly intervals up to 24 months. The monkeys and rabbits were exposed to the dust until they died.

(b) Dust.-The dust used in this experiment was a fine chrysotile dust obtained from a mine in Swaziland. A chemical analysis of this fibre showed the presence of $44 \%$ silica, $37 \%$ magnesium oxide, and $3 \%$ iron in the form of ferric and ferrous oxide. No quartz was detected by $x$-ray diffraction.

(c) Dust Count.-The average dust concentration was 37,600 particles per $\mathrm{ml}$. The particle size analysis of the thermal precipitator samples is given in the Table.

\section{Experiment II: Amosite.}

(a) Animals.-Sixteen guinea-pigs, four rabbits, and three Vervet monkeys were exposed to amosite dust collected in a Transvaal mine. The guinea-pigs were killed at monthly intervals, and the surviving rabbits and monkeys were removed from dust exposure after 14 months and allowed to die from natural causes.

(b) Dust.-This asbestos was obtained from a Transvaal amosite mine. Chemical analysis demonstrated $51 \cdot 2 \%$ silica and $24.8 \%$ iron. $7 \%$ free silica was shown by $x$-ray diffraction.

(c) Dust Counts.-Average dust concentration was 30,000 particles per $\mathrm{ml}$. The particle size analysis is given in the Table.

\section{Experiment III: Impure Crocidolite.}

(a) Animals.-Sixteen guinea-pigs, two rabbits, and four Vervet monkeys were exposed to a crocidolite mill dust. It was planned to start killing the animals after six months of dusting, but unfortunately only four animals survived this period.

(b) Dust.-A very impure crocidolite dust was obtained from a mill in the North Western Cape Province. It was found by $x$-ray diffraction to contain $50 \%( \pm 10 \%)$ quartz and less than $10 \%$ crocidolite. Chemical analysis showed $35 \%$ iron, $46 \%$ total silica.

(c) Dust Count.-Average dust concentration was 30,000 particles per $\mathrm{ml}$. The particle size analysis is given in the Table. 


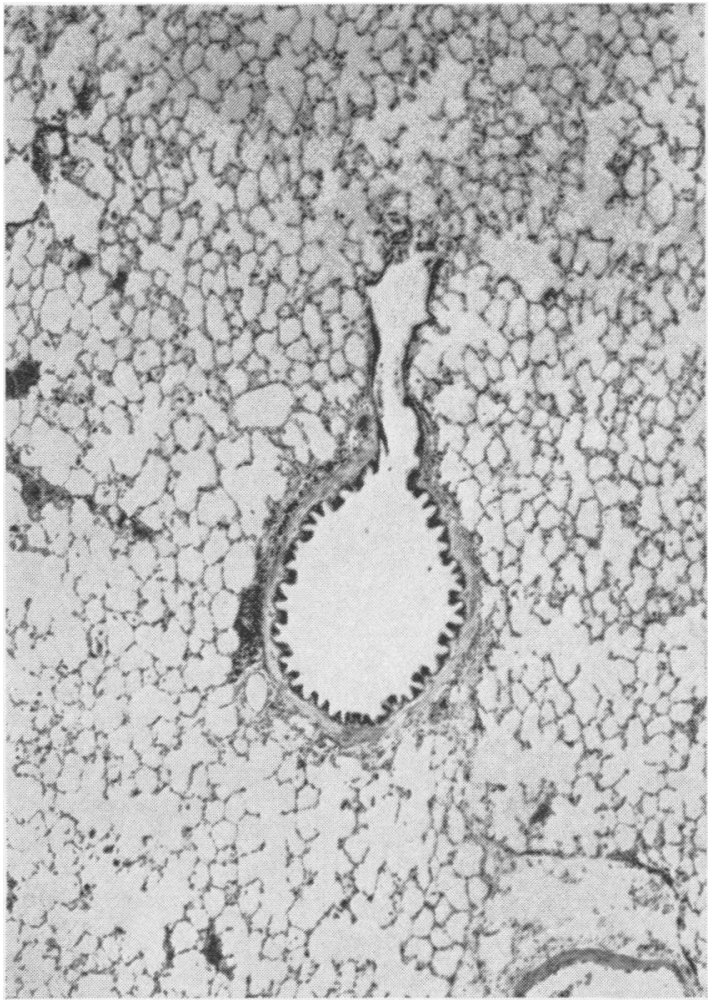

Fig. 1.-Section from lung of guinea-pig exposed to chrysotile dust for one month. (H. and E. $\times 49$.)

\section{Results}

(a) Guinea-pigs

Experiment I: Chrysotile.-These animals were killed at monthly intervals. The first evidence of macroscopic change occurred at about the tenth month, when it was found on opening the thorax that the lungs failed to collapse. At the fifteenth month the lungs were firm to the touch, while at the eighteenth month they were definitely fibrosed. At this stage, ascites and chronic venous congestion of the liver and spleen were observed. By the twentysecond month the features of cor pulmonale were more marked and there was anasarca.

Histological sections from the lungs of the first animal showed scattered phagocytes containing dust in the air spaces (Fig. 1). In some respiratory bronchioles there were small aggregations of up to six phagocytes. A few multinucleated giant cells were observed. Occasional phagocytes contained solitary segmented asbestos bodies. In the second animal the phagocytes were far more numerous especially in the respiratory bronchioles. In some of the bronchioles, aggregations of phagocytes had occurred, and occasional reticulin fibres were seen in these clumps. The multinucleated giant cells were more numerous than in the previous sections. Minute fragments of asbestos fibres and occasional small-beaded asbestos bodies were seen in the phagocytes and giant cells. In the third animal changes were found in isolated respiratory bronchioles. There was reticulin proliferation among the phagocytes adherent to the walls of the respiratory bronchioles and among those in the alveoli, arising directly from the bronchioles. The walls of these bronchioles showed slight thickening with occasional fibroblasts and a slight increase of reticulin fibres. By the fourth month, this thickening of the walls extended to those alveoli arising directly from the respiratory bronchioles (Figs. 2 and 3). Sections from animals killed in the next few months showed a gradual progress of these lesions. In all these sections very scanty segmented asbestos bodies were observed mainly in the air spaces, with occasional bodies in the interstitial tissues.

At first only individual respiratory bronchioles were involved in scattered primary units, but gradually more and more became affected until all the respiratory bronchioles in discrete secondary lobules became involved. The increased reticulinization gradually spread out from the respiratory bronchioles to involve the walls of the adjacent air spaces, and by the seventh month occasional respiratory bronchioles were connected by a reticulin network. An increase of reticulin fibres was observed in the alveolar ducts, but the walls of the terminal air sacs were not involved. By the eighth month occasional collagen fibres first appeared in the walls of these bronchioles (Figs. 4 and 5).

In the following two animals the collagen was more pronounced, and there was a generalized increase in reticulin until a syncitial appearance was seen throughout individual lobules.

Sections from the animal, killed at the twelfth month, exhibited a linkage between the interstitial fibrosis of the individual lobules and by the fifteenth month there was a definite generalized interstitial fibrosis. Collagen was most marked in the walls of the respiratory bronchioles, but it gradually spread into the walls of the surrounding air spaces, and extended down the air passages, sparing the terminal sacs (Figs. 6 and 7). This was followed by a progressive diffuse fibrosis, and from the twenty-second month the animals began dying in right ventricular failure with marked diffuse interstitial fibrosis (Fig. 8). Dusting was stopped at the end of the second year. The last two animals survived a further four and six months respectively. There was an increase in the number of asbestos bodies in the 


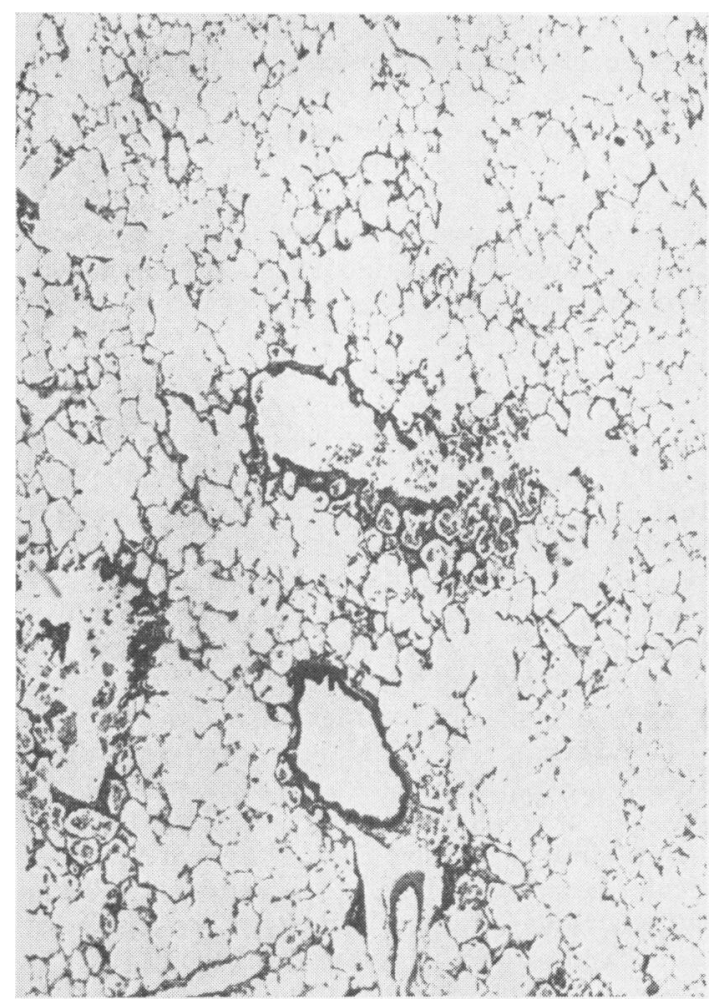

FIG. 2.-Section from lung of guinea-pig exposed to chrysotile dust for four months. (H. and E. $\times$ 49.)

section from the fifteenth month onwards, but there were never more than one or two per high power field. All the bodies were segmented.

In general, there was very little interstitial inflammatory reaction. However, a florid interstitial pneumonitis was present in the animals killed at the fourteenth, eighteenth, and twenty-second months. The infiltrate consisted of lymphocytes and plasma cells. In a number of animals there was a generalized hyperplasia of lymphoid tissue, but this did not increase with exposure, and occurred sporadically thoughout the experiment.

From the fourteenth month a cuboidal metaplasia of the epithelium of the alveolar ducts, and of the alveoli, arising directly from them and the respiratory bronchioles, was observed.

Slight pleural thickening was present in the last three animals.

\section{Experiment II: Amosite.}

Macroscopic Changes.-These were observed earlier in this experiment than in the previous one. The lungs of the animal, killed at the third month,

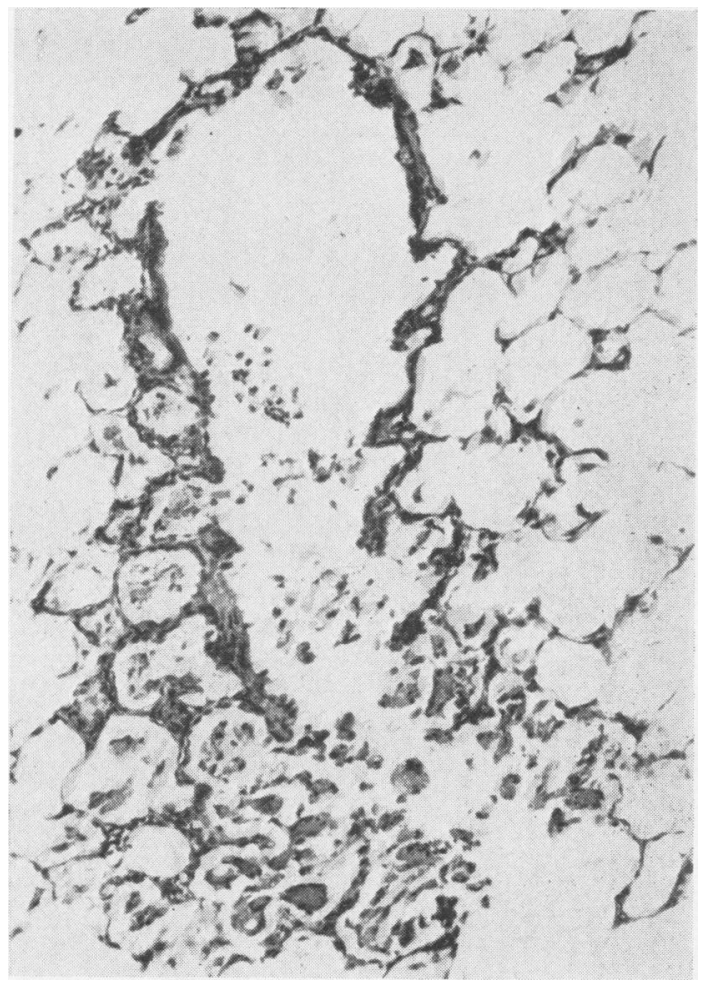

FIG. 3.-High-powered view of Fig. 2. (H. and E. $\times$ 146.)

failed to collapse when the thorax was opened, and thin pleural adhesions were present. These adhesions were a constant feature, but a "ground-glass" appearance of the visceral pleura was only observed in the last animals.

Microscopic Changes.-Comparing the histology of the lungs of these animals with that seen in the first experiment, a more marked reaction to the dust was found in the early stages. An infiltration of histiocytes and fibroblasts was seen in the interstitial tissues, and more numerous alveolar phagocytes were observed in the lumina of the respiratory bronchioles. These phagocytes tended to aggregate in the alveoli, and were filled with asbestos fibres and particles of dust which stained positively for iron. Asbestos bodies were present, becoming more numerous as the experiment progressed. Segmented bodies were seldom seen. An increase in reticulin in the walls of the respiratory bronchioles was present from the third month onwards. It invested the phagocytes (Figs. 9 and 10), and packed the alveoli of the respiratory bronchioles by the fifth month. By this time collagen had appeared. At 


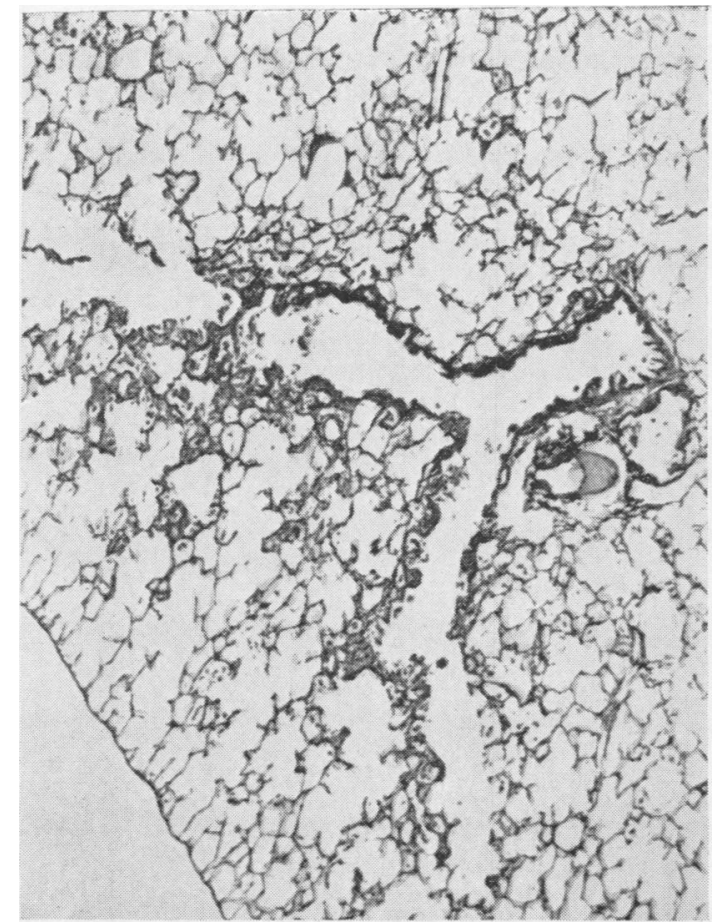

FIG. 4.-Section from lung of guinea-pig exposed to chrysotile dust for eight months. (H. and E. $\times$ 49.)

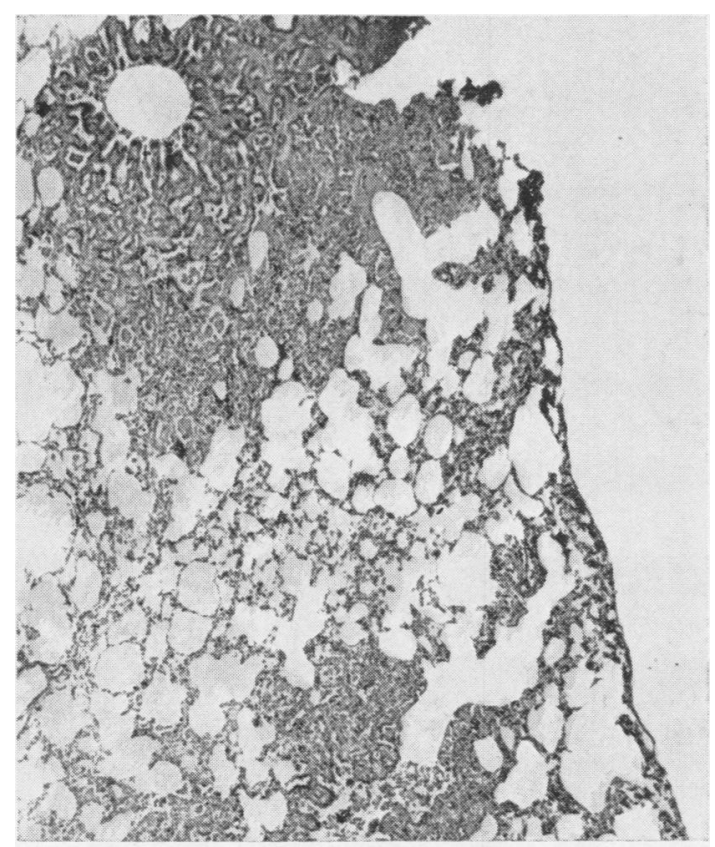

FIG. 6.-Section from lung of guinea-pig exposed to chrysotile dust for 17 months. (H. and E. $\times$ 49.)

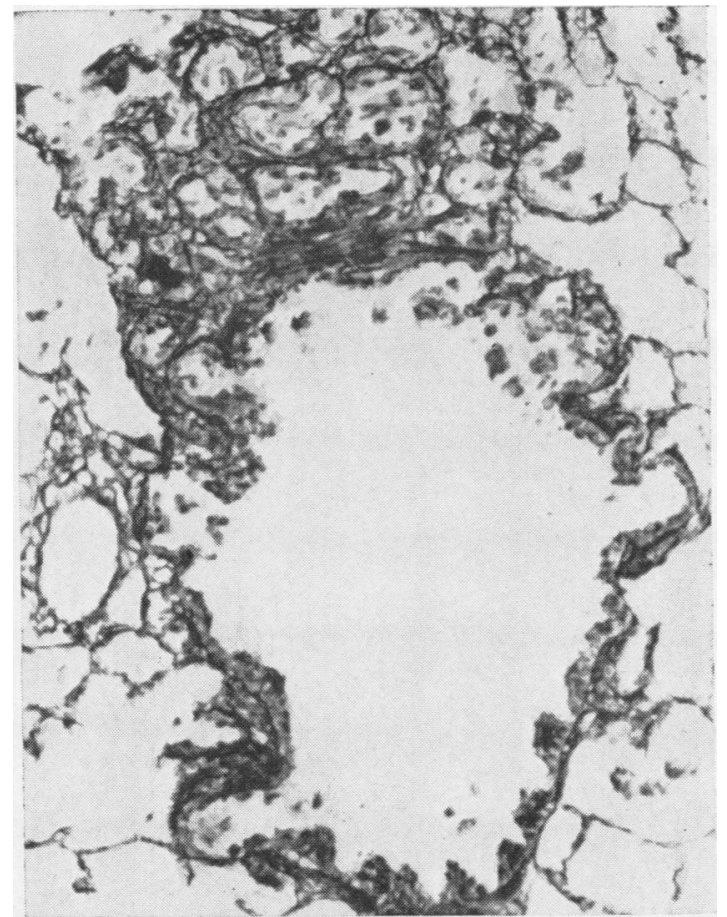

FIG. 5.-High-powered view of Fig. 4 stained to demonstrate reticulin fibres. $(x$ 146.)

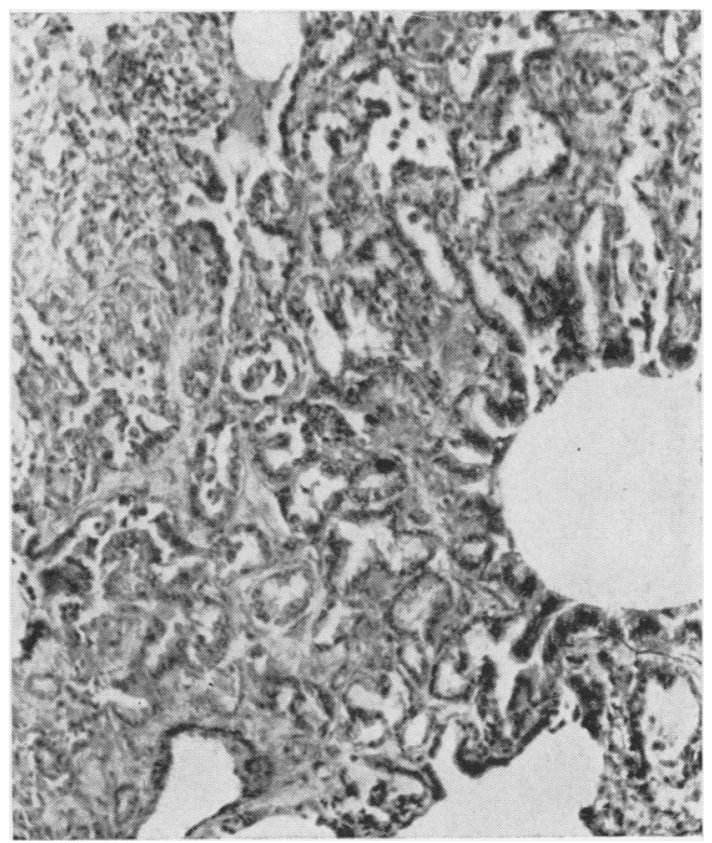

FIG. 7.-High-powered view of Fig. 6 showing pseudo-adenoid appearance. (H. and E. $\times 146$. 


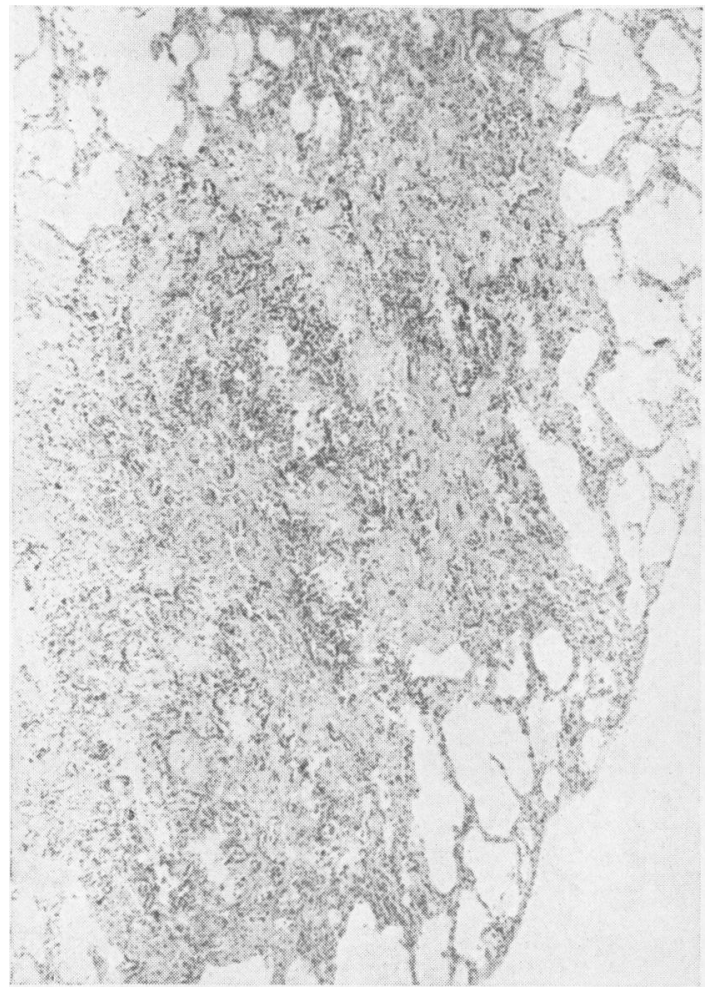

FIG. 8.-Section from lung of guinea-pig exposed to chrysotile dust for 24 months. (H. and E. $\times$ 49.)

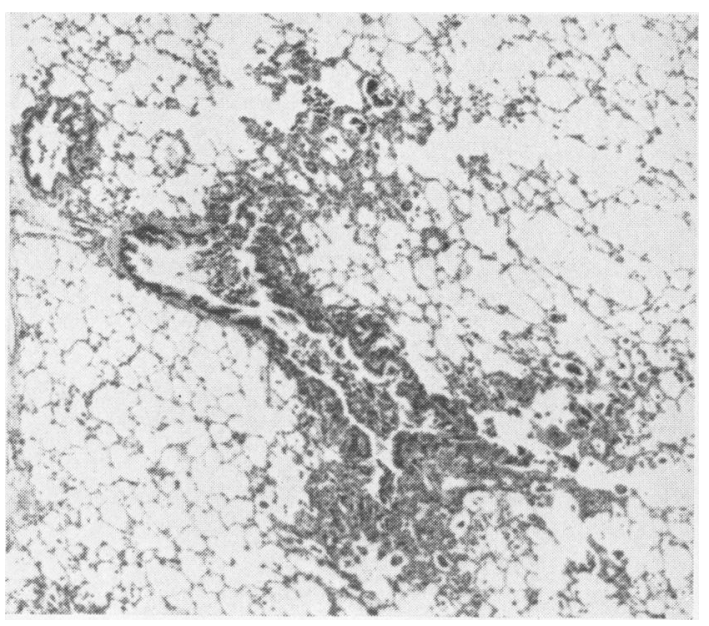

Fig. 9.-Section from lung of guinea-pig exposed to amosite dust for four months. (H. and $\mathrm{E} . \times 49$.) the eighth month confluent lesions involving entire primary lobules were seen (Figs. 11 and 12) and a diffuse interstitial fibrosis was observed at the twelfth month. In the last animal, killed at the fourteenth month, the extent of the disease was similar to that seen in a comparable animal of the previous experiment, but collagenization appeared more intense (Fig. 13).

The cuboidal metaplasia of the epithelium of the alveoli, arising from the respiratory bronchioles, was more marked, and by the seventh month this gave a

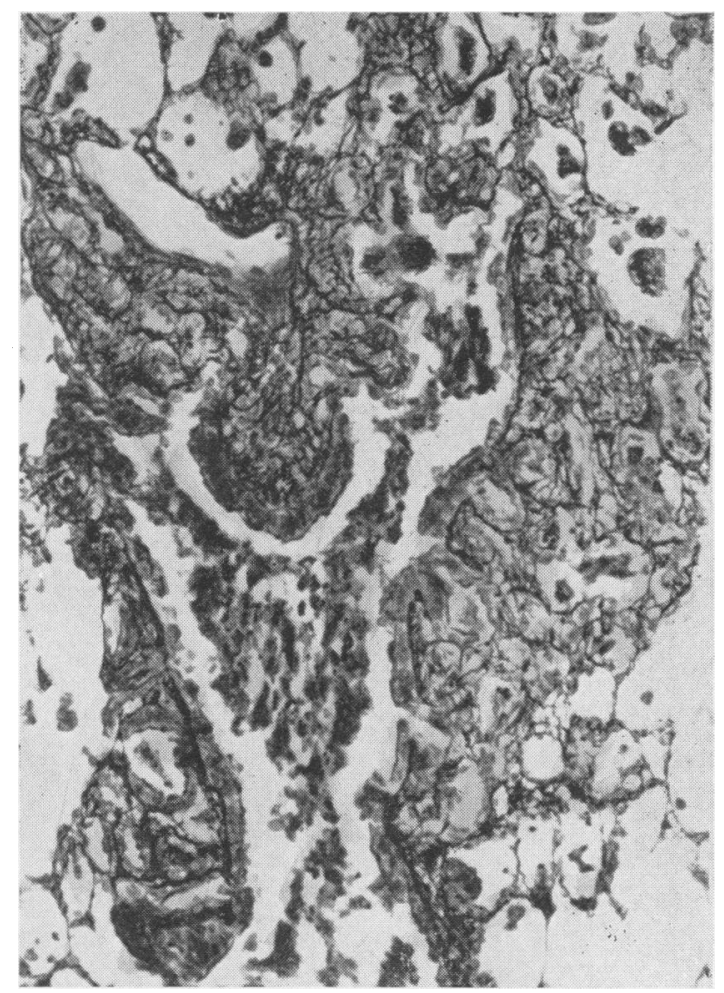

Fig. 10.-High-powered view of Fig. 9 stained to demonstrate reticulin fibres. $(x$ 146.)

pseudo-adenomatous appearance. With increasing fibrosis, this epithelium gradually disappeared, and by the fourteenth month these alveoli appeared as denuded air spaces surrounded by fibrous tissue.

Pleural changes never advanced further than a slight fibrosis of the visceral pleura.

Experiment III: Impure Crocidolite-O Owing to the extremely high rate of bronchopneumonia among these animals, it was not possible to compare their lesions with those of the two previous experi- 


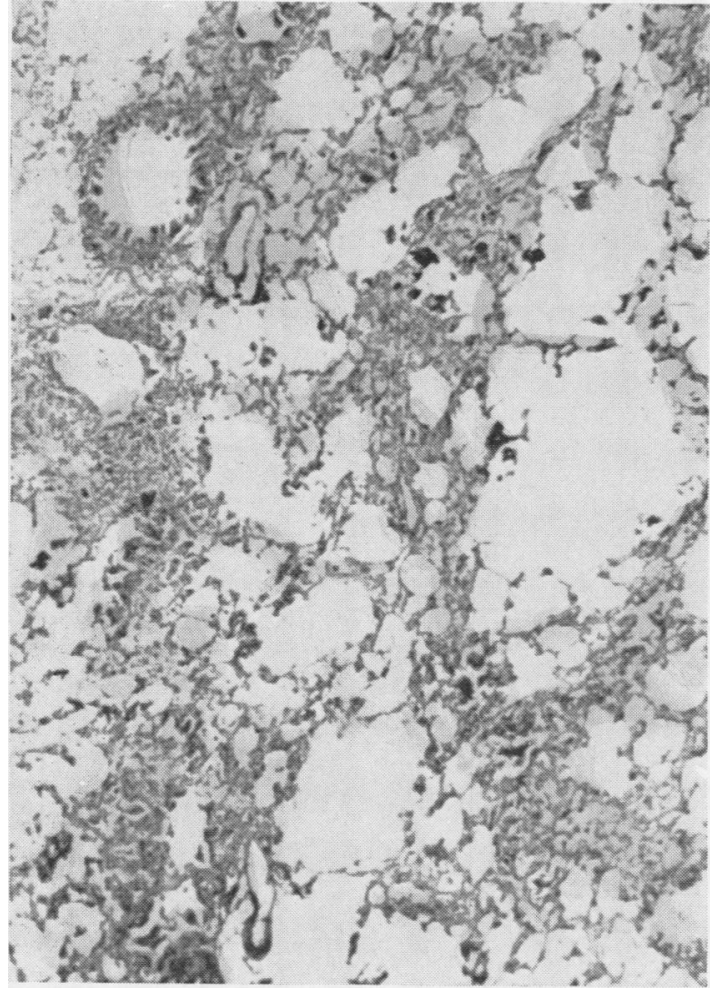

Fig. 11.-Section from lung of guinea-pig exposed to amosite dust for eight months. (H. and E. $\times 49$.)

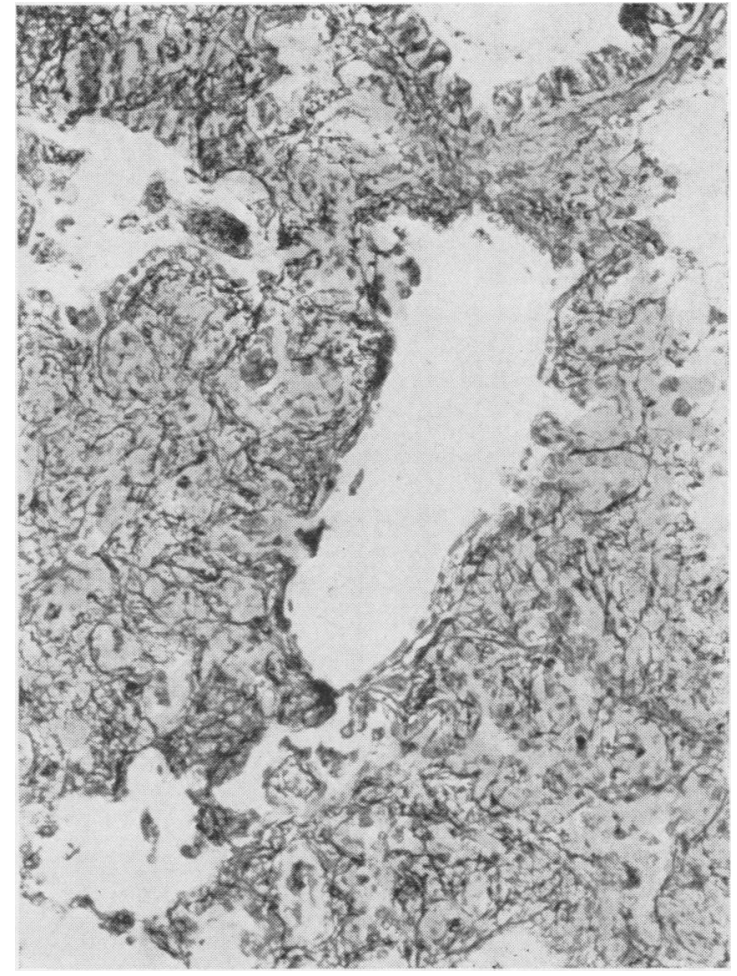

Fig. 12.-High-powered view of Fig. 11 stained to demonstrate reticulin fibres. $(\times 146$.

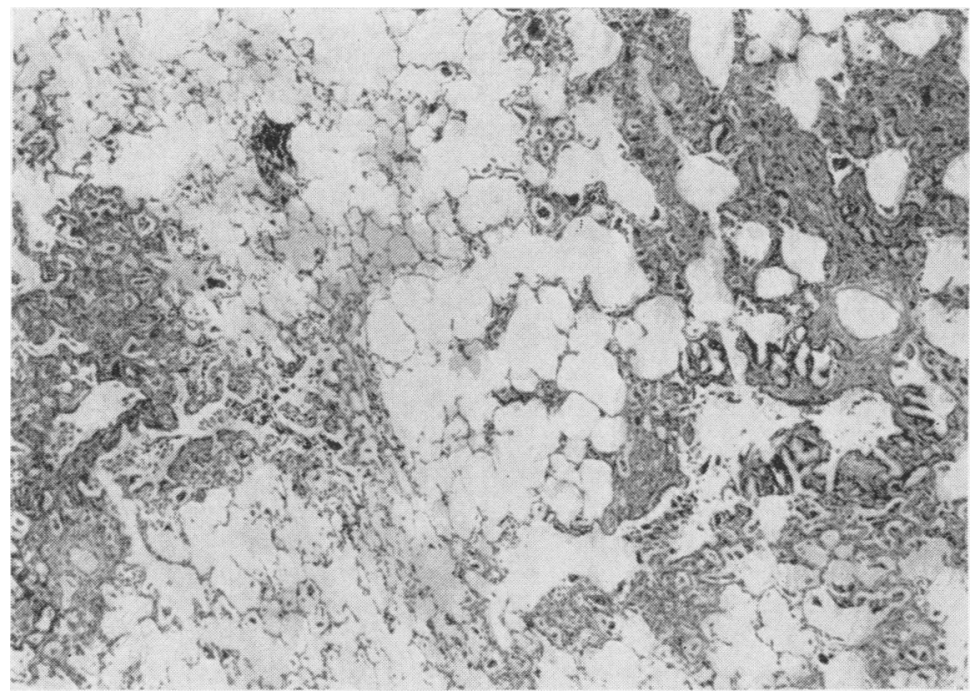

FIG. 13.-Section from lung of guinea-pig exposed to amosite dust for 14 months. (H. and E. $\times$ 49.) 


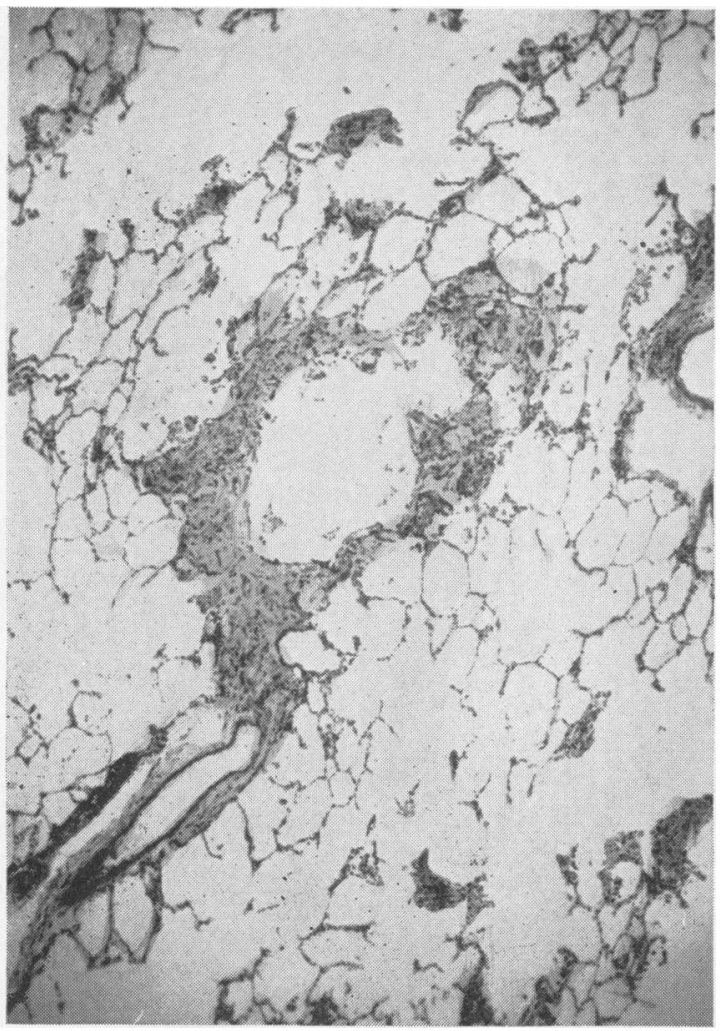

Fig. 14.-Section from lung of monkey exposed to chrysotile dust for 22 months. (H. and E. $\times$ 52.)

ments. However, histological sections, taken from non-infected portions of the lungs, demonstrated that the lesions developed in a similar manner to those seen in the animals exposed to the amosite dust.

\section{(b) Monkeys}

Experiment I: Chrysotile.-Three monkeys were exposed to chrysotile dust until they died. They survived for periods of seven, 10 , and 22 months respectively. The first two animals died of gastroenteritis. Sections from the lungs of these animals showed the presence of numerous clumps of degenerating alveolar phagocytes in the respiratory bronchioles and the adjoining air spaces. Numerous fragments of asbestos fibre and small asbestos bodies were seen in the phagocytes.

In the second animal there was a slight increase of reticulin in the walls of the respiratory bronchioles. The third monkey, at necropsy, showed gross signs of cor pulmonale and congestive cardiac failure.

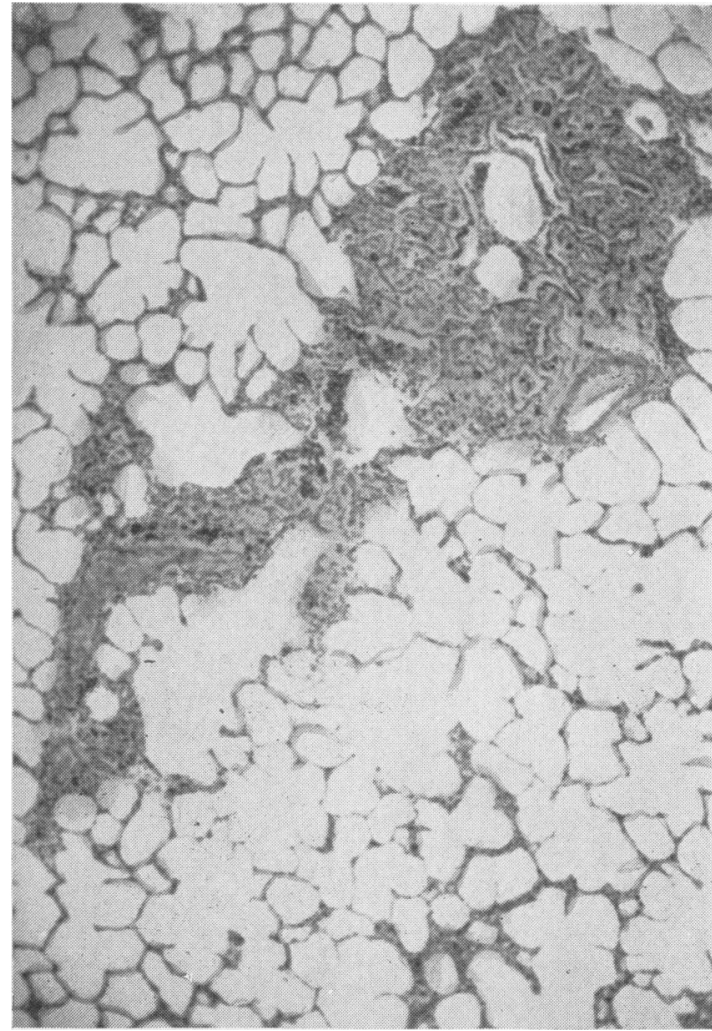

FIG. 15.-Section from lung of monkey exposed to amosite dust for four months. (H. and E. $\times 52$.)

The lungs were bulky and did not collapse when the thorax was opened, while a few thin pleural adhesions were present in both pleural sacs. On section, the lungs showed a localized fibrosis surrounding some of the larger bronchioles (Fig. 14). Segmented asbestos bodies and occasional fibres were observed in the interstitial tissues, and within the phagocytes in the air spaces.

Experiment II: Amosite.-Three monkeys were used in this experiment. The first animal died after four months' exposure. At necropsy the only significant lesions were large bulky lungs, a slightly hypertrophied right ventricle, and the features of chronic venous congestion.

Histologically, the lungs showed features comparable to those seen in a slight degree of human asbestosis. There was a fairly marked fibrosis of the walls of the respiratory bronchioles and their alveoli, with a slight increase of reticulin in the walls of the peribronchiolar air spaces (Fig. 15). Numerous asbestos bodies and large masses of fibres were seen 

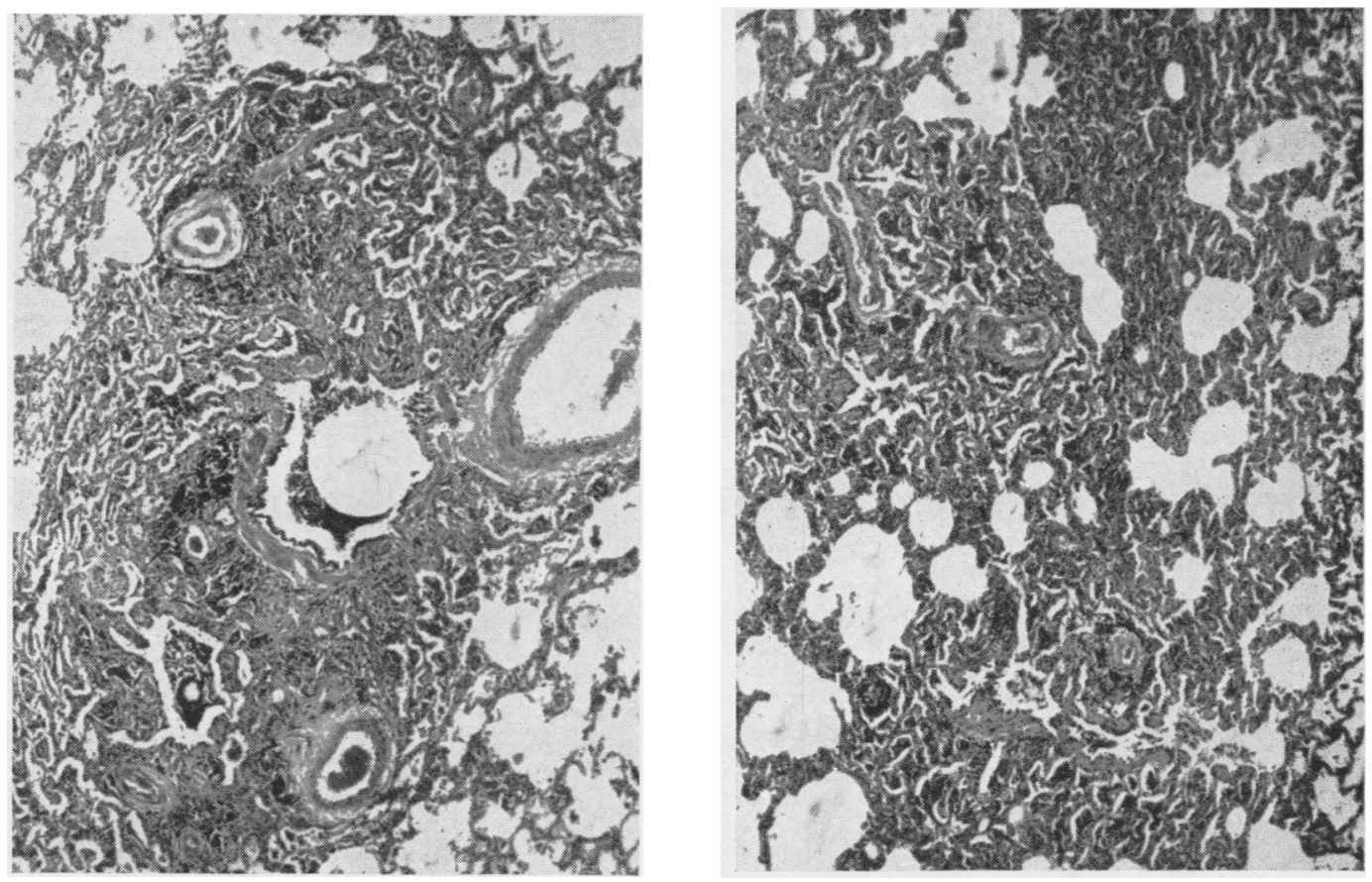

Fig. 16 and Fig. 17.-Section from lung of monkey exposed to amosite dust for 14 months and rested for a further four months. (H. and E. $\times$ 45.)

in the interstitial tissues, and in the air spaces. The second animal which died after 12 months exhibited features of cor pulmonale. Macroscopically, the lungs were definitely indurated. Histologically, there was a diffuse increase of reticulin fibrils, with an increase of collagen in the region of the respiratory bronchioles. These features were consistent with those of a moderate degree of human asbestosis.

The third animal was exposed to the dust for 14 months and survived for a further four months. At necropsy, features of right heart failure were observed. The heart was examined in a similar manner to that described by Becker and Chatgidakis (1960). The heart weighed $20.9 \mathrm{~g}$. The left ventricle weighed $7.5 \mathrm{~g}$. and the right $7.8 \mathrm{~g}$., giving a ratio of $1: 1$. The right auricle was dilated. It is presumed that these findings indicate the presence of a cor pulmonale. Unfortunately, the normal range of heart weights has never been calculated in this species of monkey.

The lungs felt indurated, with dense adhesions nearly obliterating both pleural cavities. Histological examination showed marked diffuse interstitial fibrosis, with areas of fibrosis in the region of the respiratory bronchioles (Figs. 16, 17, and 18).

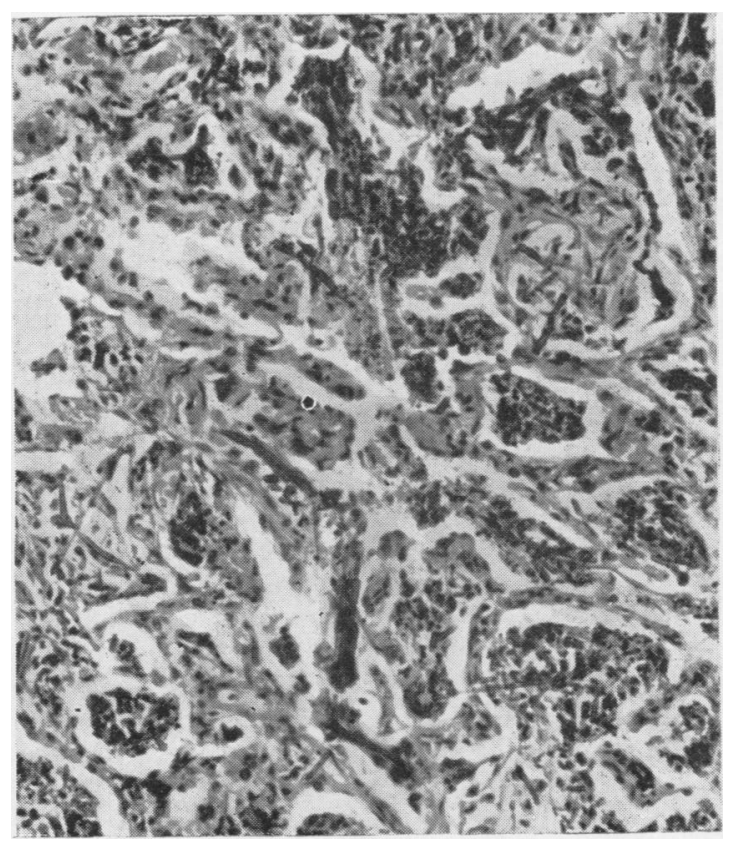

FIG. 18.-High-powered view of Fig. 17 showing asbestos bodies and fibres in lesions. (H. and E. $\times$ 183.) 


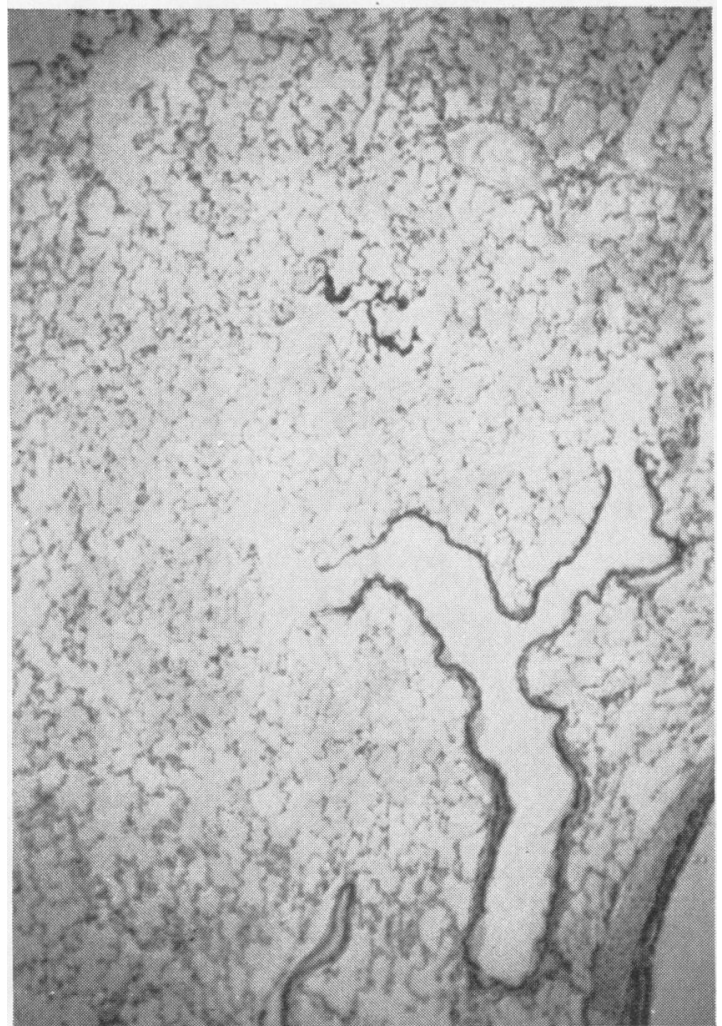

Fig. 19.-Section from lung of normal rabbit. (H. and E. $\times 55$.)

The histological features were consistent with those of a moderate to marked degree of human asbestosis.

Experiment III: Impure Crocidolite.-Four monkeys were exposed and died at the fourth, sixth, seventh, and tenth months of dusting. All died of bronchopneumonia. Histological sections were taken from sites free of inflammatory lesions.

In the first animal there was an increase of reticulin in the walls of the respiratory bronchioles, which extended into their alveoli. These alveoli, and the surrounding air spaces, were packed with dust that consisted of early asbestos bodies and fibres and considerable amounts of iron-containing particles. This dust was mainly lying free, although some was contained in phagocytes, There was some organization of the dust, as was shown by the presence of reticulin fibres. In the following two animals there was an increase of the interstitial tissues of the respiratory bronchioles, and a more marked organization of the dust deposits in the air spaces.

The animal dying at the tenth month (having been

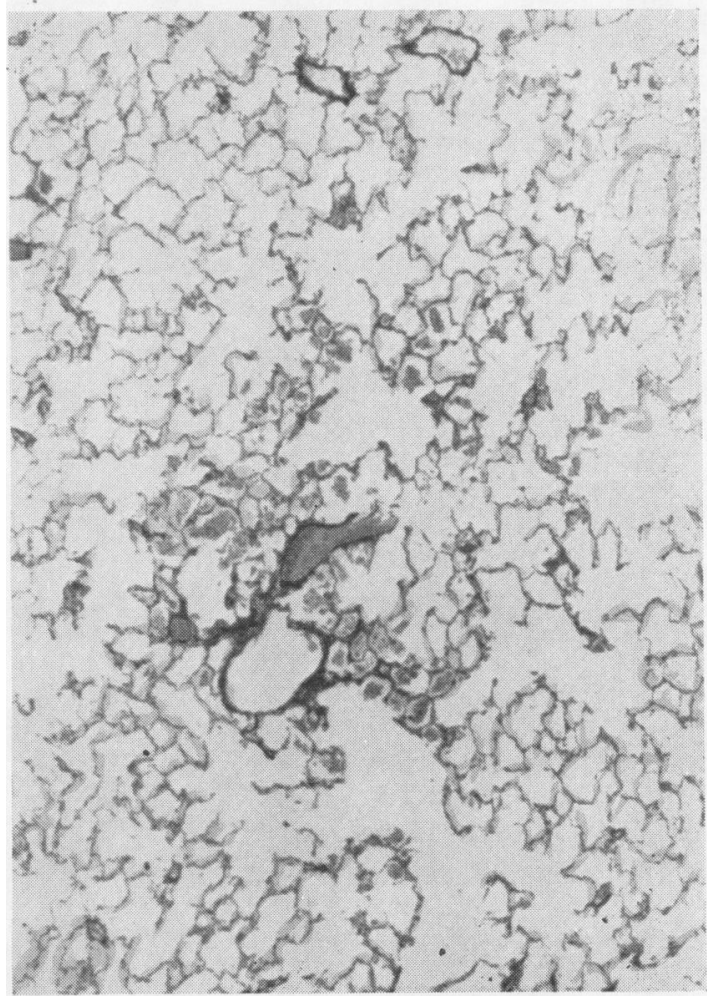

FIG. 20.-Section from the lung of rabbit exposed to chrysotile dust for 14 months. (H. and E. $\times$ 49.)

exposed to dust for seven months and rested for three) showed the features of congestive cardiac failure. The heart appeared to be enlarged, with dilatation of the right auricle, and moderate hypertrophy of the right ventricle. The heart weighed $16 \mathrm{~g}$. The left ventricle weighed $5.25 \mathrm{~g}$. and the right $3.52 \mathrm{~g}$., giving a ratio of $1.5: 1$. There were pleural adhesions, with the lungs appearing indurated, and there was a confluent pneumonia in the right middle lobe.

Histological sections demonstrated interstitial fibrosis which was confined mainly to the vicinity of the respiratory bronchioles, but in a few foci the fibrosis was widespread. There was a slight thickening of the pleura, with two early asbestotic plaques over the surface of the left lower lobe. As in most of the other animals the lung lesions were widespread, the upper and lower lobes being equally involved.

\section{(c) Rabbits}

In support of Loosli (1938), no respiratory 


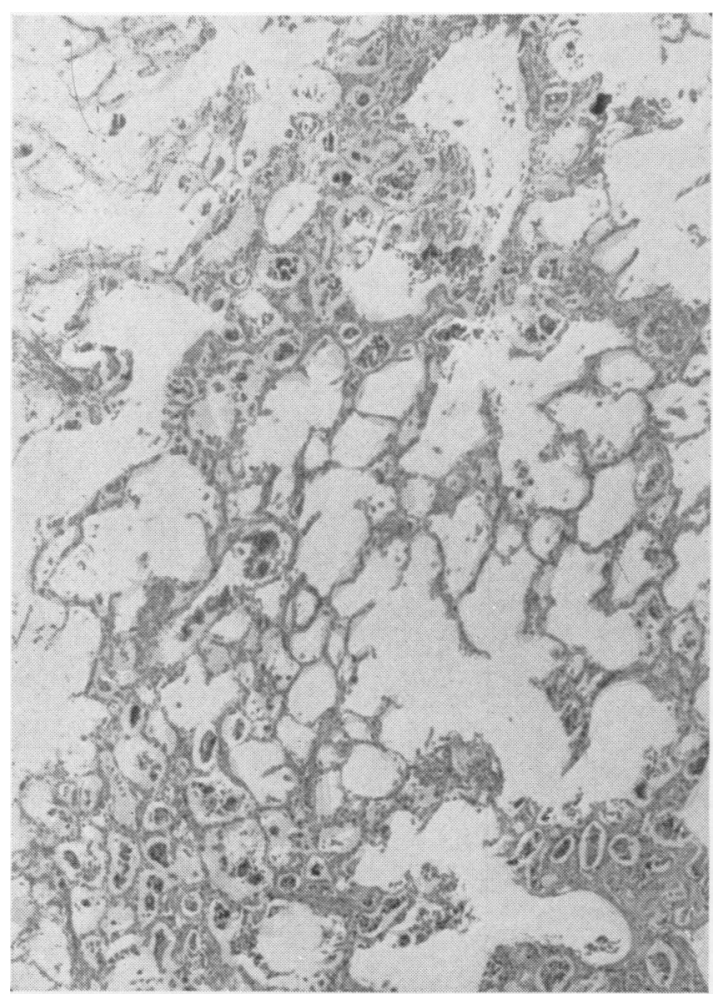

FIG. 21.-Section from lung of rabbit exposed to amosite dust for 14 months, and rested for two months. (H. and E. $\times 49$.)

bronchioles have been observed in sections from the rabbits' lungs. The terminal bronchioles appear to communicate directly with the alveolar ducts (Fig. 19).

Two rabbits were exposed to chrysotile, four to amosite, and two to crocidolite dust.

Experiment I: Chrysotile.-The first of these animals was killed after 14 months' exposure to the dust.

Histological examination of the lungs showed accumulations of multinucleated alveolar phagocytes in the vicinity of the alveolar ducts (Fig. 20), but no significant change in the interstitial tissues was demonstrated. Similar features were observed in an animal that died three months later.

Experiment II: Amosite.-The first rabbit died after a period of two months' dusting, but unfortunately the tissue was unsuitable for histological examination due to autolysis. The remaining animals were exposed to the dust for 14 months and then "rested". They survived for a further two, eight, and 28 months respectively.

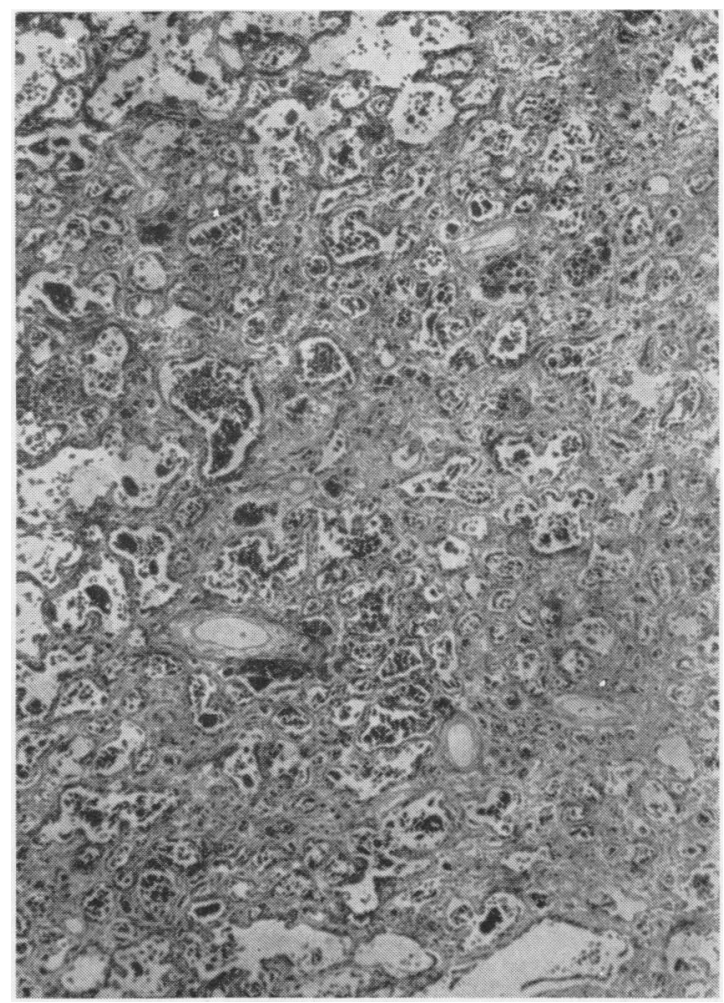

FIG. 22.-Section from lung of rabbit exposed to amosite dust for 14 months, and rested for 28 months. (H. and E. $\times 49$.)

In the lungs of the second animal there was a fairly marked interstitial fibrosis, mainly involving the alveolar ducts, with trapping of the phagocytes in the alveoli arising from them (Fig. 21). In these phagocytes, numerous asbestos bodies, fibres, and small fragments of fibre were seen. Fibres and asbestos bodies were observed in the walls of the alveolar ducts. In the third animal, there was a generalized interstitial fibrosis with marked fibrotic lesions involving the alveolar ducts. The lungs of the fourth animal showed the features of a marked generalized interstitial fibrosis (Fig. 22).

Experiment III : Impure Crocidolite.-Both animals died of widespread bronchopneumonia and, although a considerable amount of dust was observed in the sections, it was not possible to comment on the effects of the asbestos.

\section{Discussion}

With chrysotile dust it was possible to produce severe lesions in the lungs of guinea-pigs, slight fibrosis in monkeys, while no significant effect was observed in two rabbits. Amosite dust causes 
marked asbestosis in all three kinds of animals. Lesions occur more rapidly in guinea-pigs exposed to this dust than in those exposed to chrysotile. There is an indication that the disease is progressive in monkeys and rabbits. Similar pathology to that which occurred in a monkey exposed to chrysotile for 22 months was observed in a monkey exposed to amosite for four months. The impure crocidolite dust caused severe disease in guinea-pigs, and the rate of respiratory infection among animals exposed to this dust was more marked than with the other types. It is possible that this may be due to the high quartz content of the dust.

Finally, asbestos bodies could be demonstrated in the lungs of animals exposed to all three types of asbestos dust. These were scanty in the animals exposed to chrysotile and usually segmented. Only occasional fibres were observed. In contrast to this, the asbestos bodies in the animals that were dusted with amosite were plentiful, and segmentation was rare; fibres were extremely numerous and far outnumbered the bodies.

These experiments were undertaken as preliminary investigations. The effects of various other asbestos dusts are being examined. In these later studies, which are being conducted on a statistical basis, there will be chemical analyses of the lungs and more definite physical and chemical characterization of the dust clouds.
I wish to thank Dr. Ian Webster for his suggestion that I should carry out these experiments, and for his encouragement and all facilities.

I am most grateful to the following: Mr. Kitto, Director of the Chamber of Mines Dust and Ventilation Laboratories and his staff for the dust counts on the first experiment and the $x$-ray diffraction analyses of the dusts; Dr. W. van Biljon for great assistance in the geology and mineralogy of asbestos; The Asbestos Producers of South Africa for supplying the dusts; and finally, the numerous members of the staff of this Unit who have assisted in this work.

\section{REFERENCES}

Becker, B. J. P., and Chatgidakis, C. B. (1960). In Proceedings of the Pneumoconiosis Conference, Johannesburg 1959, ed. A. J. Orenstein, p. 205. Churchill, London.

Gardner, L. U. (1938). In Silicosis and Asbestosis, ed A. J. Lanza, p. 323. Oxford University Press, New York and London. p. 32. Oxford University Press, New York and Lo

$\overline{\text { Hunter, D. (1957). The Diseases of Occupations, } 2 \text { nd ed., pp. } 906-910 .}$ English Universities Press, London.
End

King, E. J., Clegg, J. W., and Rae, V. M. (1946). Thorax, 1, 188.

Loosli, C. G. (1938). Amer. J. Anat., 62, 375.

Simson, F. W. (1928). Brit. med. J., 1, 885.

Smith, J. M., Wootton, I. D. P., and King, E. J. (1951). Thorax, 6, 127.

Vorwald, A. J., Durkan, T. M., and Pratt, P. C. (1951), A.M.A. Arch. industr. Hyg., 3, 1 .

Wagner, J. C. (1958). In Die Staublungenerkrankungen (Ber. 3 int Staublungen-Tagung, Munster, 1957), ed. K.W. Jötten and W.

Staublungen-Tagung, Munster, 1957), ed. K. W. Jötten and W.
Klosterkötter, Vol. 3, p. 566. Steinkopf, Darmstadt. (1960). In Proceedings of the Pneumoconiosis Conference,
Johannesburg 1959, ed. A. J. Orenstein, p. 380. Churchill, London.

Webster, I. (1954). Proc. Transv. Mine med. Offrs' Ass., 34, 33. 